\title{
Peningkatan Literasi Sekolah Guru dan Siswa melalui Pengabdian Kepada Masyarakat Perpustakaan STIE Perbanas Surabaya
}

\author{
Melati Purba Bestari \\ STIE Perbanas Surabaya \\ melati@perbanas.ac.id \\ M.Hudhan Hakiki \\ STIE Perbanas Surabaya \\ hudhan.hakiki@perbanas.ac.id
}

\begin{abstract}
The phenomenon of information explosion supported by the development of information technology to overcome the required information literasi kemapuan. The ability of information literacy to support the activities of searching, evaluating, and using information appropriately. Information literacy should be owned by the academic community not excluded the school community for teachers and students. The existence of Permendikbud No.23 of 2015 requires schools to carry out activities "School Literacy Movement includes basic literacy, library, media technology and libraries, and sharing opportunities with representatives of teachers in Counseling Teacher Consultative Forum (MGBK) Surabaya Library STIE Perbanas Surabaya held community service activities related to school literacy improvement. The target schools include SMAN 15 Surabaya and SMA Wachid Hasyim 1. Literacy improvement activities include sharing information literacy activities with teachers, librarian lectures and competence activities of short story competitions. The results of the service activities include the establishment of cooperation related to the development of school literacy contained in the MoU, students' understanding of school literacy which reached 63\% and the publication of a collection of short stories ISBN.
\end{abstract}

Keywords: school lite movement, information literacy, library service to the community 


\begin{abstract}
Abstrak
Fenomena ledakan informasi yang didukung dengan perkembangan teknologi informasi untuk mengatasinya diperlukan kemapuan literasi informasi. Kemampuan literasi informasi mendukung kegiatan menelusur, mengevaluasi, dang menggunakan informasi secara tepat. Literasi informasi harus dimilik oleh masyarakat akademin tidak terkecual masyarakat sekolah bagi untuk guru maupun siswa. Adanya Permendikbud No.23 Tahun 2015 mewajibkan sekolah-sekolah untuk melaksanakan kegiatan "Gerakan Literasi Sekolah meliputi literasi dasar, perpustakaan, media teknologi dan perpustakaan, dan kesempatan sharing dengan perwakilan guru dalam Musyawarah Guru Bimbingan Konseling (MGBK) Surabaya maka Perpustakaan STIE Perbanas Surabaya mengadakan kegiatan pengabdian masyarakat terkait peningkatan literasi sekolah. Adapun sekoah yang menjadi target diantaranya SMAN 15 Surabaya dan SMA Wachid Hasyim 1. Kegiatan peningkatan literasi meliputi sharing kegiatan literasi informasi dengan guru, ceramah perpustakaan dan aktivitas kompetis lomba cerpen. Adapun hasil dari kegiatan pengabdian diantaranya terjalinnya kerjasama terkait dengan pengembangan literasi sekolah yang tertuang pada MoU, pemahaman siswa terhadap literasi sekolah yang mencapai 63\% dan penerbitan kumpulan cerpen ber-ISBN.
\end{abstract}

Kata Kunci: gerakan liteasi sekolah, literasi informasi, pengabdian perpustakaan kepada masyarakat.

\title{
Pendahuluan
}

Kemajuan teknologi informasi yang terjadi saat ini menimbulkan adanya ledakan informasi (information explotion), hal tersebut wajar terjadi karena adanya ledakan informasi menandakan adanya perkembangan fenomena informasi yang didukung dengan adanya perkembangan teknologi informasi. Adanya ledakan informasi ini menimbulkan tidak adanya keterbatasan ruang,waktu dan tempat dalam melakukan akses informasi karena akses dapat dilakukan dimana saja, kapan saja dengan memanfaatkan teknologi informasi.

Dalam mengatasi ledakan informasi yang terjadi di masyarakat terutama pada masyarakat sekolah diperlukan adanya pemahaman literasi informasi di lingkungan sekolah. Literasi informasi perlu dipahami oleh 
masyarakat sekolah tidak terkecuali pada siswa-siswi. Kegiatan literasi selama ini identik dengan aktivitas membaca dan menulis. Namun, Deklarasi Praha pada tahun 2003 menyebutkan bahwa literasi juga mencakup bagaimana seseorang berkomunikasi dalam masyarakat. Literasi juga bermakna praktik dan hubungan sosial yang terkait dengan pengetahuan, bahasa, dan budaya. (Candy, 2002)

Seseorang yang terampil dalam literasi informasi mengenal waktu saat membutuhkan informasi serta memiliki kemampuan dalam melakukan penelusuran sampai dengan informasi ditemukan, dan mampu melakukan evaluasi, serta mampu menggunakan informasi guna menentukan pengambilan keputusan yang tepat. Individu yang memiliki informasi literasi akan menjadi pribadi yang memiliki rasa percaya diri, kemandirian, penuh inisiatif, dan memiliki motivasi tinggi dalam melakukan berbagai aktivitas. Selain itu, individu yang memiliki literasi informasi mengetahui cara belajar dan terus melakukan upaya untuk melakukan lifelong learning (belajar sepanjang masa).

Ketika literasi informasi sudah dikuasai individu akan lebih mudah dalam memanfaatkan informasi, lebih mudah dalam mengimplementasikan kreatifitas kerena telah menguasai sumber-sumber informasi yang mendukung terciptanya kreatifitas dan juga dapat mendorong pencapaian kesuksesan akademik dari masyarakat akademik yakni berupa prestasi secara akademis maupun non akademis. (Ranaweera, 2008)

Dukungan perpustakaan dalam mendukung penciptaan atmosfer akademik yang baik dan positif dapat dilakukan dengan membuat aktivitas literasi informasi untuk masyarakat akademik. Pentingnya penguasaan literasi informasi oleh masyarakat akademik diperlukan untuk dapat mendukung pencapaian kesuksesan akademik maupun non akademik. Apabila masyarakat akademik sudah berliterasi, mereka akan dapat memanfaatkan segala bentuk informasi yang sudah melalui proses evaluasi untuk menjadi sebuah karya atau kreatifitas.Tantangan pustakawan yang memberikan pelayanan kepada masyarakat akademis terutama di perguruan tinggi adalah mendukung kegiatan tri dharma perguruan tinggi diantaranya kegiatan pengabdian kepada masyarakat 
Siswa-siswi saat ini merupakan net generation atau generasi internet lahir di era telah berkembangnya internet yakni dikisaran tahun 1990-an, tentunya yang lahir di era ini memiliki perilaku pencarian informasi yang signifikan. Apabila dikemas dalam bentuk poin-poin, adapun perilaku pencarian informasi dari generasi ini antara lain:

- net generation ingin berhasil dengan melakukan sedikit usaha dan pengorbanan

- net generation lebih percaya dengan teman yang sebaya dibandingan dengan pihak yang memiliki otoritas yang formal.

- net generation lebih menyukai kebebasan untuk melakukan ekspresi diri - net generation lebih memiliki banyak tuntutan

- net generation lebih sering berkomunikasi dengan teks dan jejaring sosial. (Suryani, 2013)

Melihat perkembangan informasi yang saat ini terjadi dan karakter siswa-siswi di jenjang sekolah menengah atas (SMA) yang merupakan net generation, maka untuk memenuhi kebutuhan informasi mereka yang cukup tinggi dalam mendukung kegiatan belajara dan mengajar maupun dalam mengembangan kreatifitas mereka diperlukan kemampuan literasi informasi yang harus dikuasai oleh siswa-siswi.

Dengan adanya Permendikbud No.23 Tahun 2015 mewajibkan sekolah-sekolah untuk melaksanakan kegiatan "Gerakan Literasi Sekolah", adapun aktivitas Gerakan Literasi Sekolah yang harus dijalankan meliputi:

a. Literasi Dasar

Membaca 15 menit sebelum kegiatan belajar mengajar setiap hari, setelah itu mendiskusikan bacaan yang sudah di baca dengan teman ataupun guru, lalu menuliskan analisis terhadap bacaan yang selesai di baca dan di diskusikan.

b. Literasi Perpustakaan

Mencari bahan pustaka yang diminati untuk kegiatan membaca 15 menit, setelah itu para siswa dapat menggunakan Perpustakaan sebagai sumber informasi dalam diskusi tentang bacaan, dan tidak lupa agar para siswa/ 
siswi dapat mencantumkan daftar pustaka untuk dicantumkan dalam tulisan mereka dan nantinya juga terhadap laporan tugas/ praktik setiap mata pelajaran yang ditugaskan.

c. Literasi Media

Membaca berita dari media cetak/daring dalam kegiatan membaca 15 menit, setelah itu mendiskusikan berita dari media cetak/daring, dan yang terakhir diharapkan siswa-siswi agar dapat membuat kelompok belajar untuk diskusi dan berbagi informasi terkait pemahaman mata pelajaran.

d. Literasi Teknologi

Membaca buku elektronik/digital, setelah itu memberikan komentar terhadap buku elektronik/digital yang sudah dibaca, dan yang terakhir supaya siswa-siswi mampu mengimplementasikannya kepada setiap mata pelajaran dan tak lupa memanfaatkan teknologi (computer, searching, dan share) dalam mengolah, menyaji, melaporkan hasil kegiatan/laporan.

e. Literasi Visual

Membaca film atau iklan pendek, lalu mendiskusikan film atau iklan pendek dengan teman ataupun guru, dan yang terakhir diharapkan siswa-siswi nantinya dapat menggunakan aplikasi video/film dalam menyaji dan melaporkan kegiatan hasil praktik/diskusi/observasi melalui website sekolah, youtube, dll. (Direktorat Jenderal Pendidikan Dasar dan Menengah Kementerian Pendidikan dan Kebudayaan, 2016)

Berawal dari kesempatan Perpustakaan STIE Perbanas Surabaya yang memiliki kesempatann untuk berdiskusi mengenai literasi sekolah pada acara Musyawarah Guru Bimbingan Konseling (MGBK) Surabaya diantaranya SMAN 15 Surabaya dan SMA Wachid Hasyim Surabaya menyampaikan kegiatan literasi yang sudah sekolah mereka jalankan. Dari beberapa perwakilan sekolah yang melakukan diskusi dapat dilihat bahwa sebagian besar sekolah sudah melaksanakan gerakan literasi sekolah tingkat dasar yakni gerakan 15 menit membaca sebelum melakukan belajar mengajar.

Dalam menciptakan sarana untuk mendukung Life Long Education, manajemen Perpustakaan Sekolah harus di kelola secara professional dengan 
kegiatan-kegiatan Literasi Informasi di dalamnya, sehingga Perpustakaan Sekolah tercipta bukan hanya sebagai sumber belajar akan tetapi mengajarkan siswa-siswi dalam pengelolaan sumber informasi yang mereka dapat, seperti yang di paparkan dalam Buku Saku Gerakan Literasi Sekolah yang di terbitkan Oleh Depdiknas agar para siswa-siswi mempunyai kemampuan Dalam mengakses, Memahami, Menggunakan dan Memanfaatkan Informasi yang mereka peroleh secara Cerdas dan Bijak. Sehingga kemampuan Literasi Informasi akan berdampak pada :

1. Sukses dalam hal Akademik, terampil dalam menelusur informasi yang dibutuhkan untuk memecahkan masalah belajar.

2. Bijak dalam memanfaatkan Informasi yang di peroleh, mana informasi yang Hoax dan mana informasi sampah, biasanya informasi tersebut di dapat melalui google.

3. Mampu untuk menggabungkan informasi yang di pilihnya sesuai dengan landasan ilmu pengetahuan.

Melihat fenomena mengenai kegiatan literasi sekolah yang sedang marak dijalankan sekolah-sekolah dan melihat kebutuhan aktivitas literasi yang tidak hanya menjalankan literasi dasar maka Perpustakaan STIE Perbanas Surabaya melakukan kegiatan Pengabdian Masyarakat terkait meningkatkan literasi sekolah, guru dan siswa yakni di SMAN 15 Surabaya dan SMA Wachid Hasyim Surabaya.

\section{Pembahasan/Implementasi}

\section{Persiapan Kegiatan}

\section{Pemilihan lokasi kegiatan pengabdian Perpustakaan}

Target sekolah yang dipilih untuk melakukan kegiatan pengabdian yakni sekolah-sekolah yang telah melaksanakan kegiatan gerakan literasi. Pada kesempatan pemberian sosialisasi gerakan literasi sekolan pada acara MGBK kota Surabaya terdapat beberapa sekolah yang bersedia melakukan sharing kegiatan literasi sekolah yang sudah di jalankan diantaranya adalah SMAN 15 Surabaya dan SMA Wachid Hasyim Surabaya. Dilanjutkan 
dengan komunikasi informal dengan pihak perwakilan sekolah untuk penawaran kegiatan pengabdian Perpustakaan STIE Perbanas Surabaya dan setelah mendapat jawaban kesediaan secara informasi dilanjutkan dengan mempersiapkan proposal kegiatan ke masing-masing sekolah.

\section{Penyusunan proposal kegiatan pengabdian perpustakaan}

Proposal kegiatan "Pengabdian Perpustakaan STIE Perbanas Surabaya Kepada Masyarakat Melalui Membangun Atmosfer Akademik Literasi Sekolah Di SMAN 15 Surabaya dan SMA Wachid Hasyim 1 Surabaya” disusun dari hasil diskusi oleh Tim Perpustakaan STIE Perbanas Surabaya dengan mempertimbangkan kebutuhan sekolah-sekolah terkait kegiatan gerakan literasi sekolah dan juga disesuaikan dengan RKAT Perpustakaan STIE Perbanas Surabaya. Untuk waktu pelaksanaan kegiatan pihak Perpustakaan STIE Perbanas Surabaya menyerahkan pemilihan waktu yang disesuaikan dengan agenda sekolah masing-masing, hal tersebut dilakukan agar kegiatan pengabdian perpustakaan ini tidak berbenturan dengan kegiatan-kegiatan sekolah. Adapun kegiatan-kegiatan yang akan dilaksanakan antara lain:

\begin{tabular}{cllll}
\hline No & \multicolumn{1}{c}{ Nama Kegiatan } & Metode Pelaksanaan & \multicolumn{1}{c}{ Keterangan } & PIC \\
\hline 1 & $\begin{array}{l}\text { Sharing kegiatan Literasi } \\
\text { Informasi yang telah } \\
\text { dilaksanakan Perpustakaan } \\
\text { STIE Perbanas Surabaya }\end{array}$ & $\begin{array}{l}\text { 1. Ceramah } \\
\text { 2. Sharing dan Diskusi } \\
\text { tentang Kegiatan }\end{array}$ & $\begin{array}{l}\text { 1. Target : Guru-guru di } \\
\text { Sekolah tempat kegiatan }\end{array}$ & $\begin{array}{l}\text { Pustakawan STIE } \\
\text { Perbanas Surabaya }\end{array}$ \\
\hline 2. & Ceramah Perpustakaan & 1. Ceramah & 1. Target : Siswa-siswi & Pustakawan STIE \\
& & 2. Diskusi & Sekolah tempat kegiatan & Perbanas Surabaya \\
& & & berlangsung & \\
\hline 3. & Perwujudan dari Literasi & 1. Menulis Cerpen & 1. Target : Siswa-Siswi & Pustakawan STIE \\
& Dasar dan Literasi & & Membuat Cerpen dengan & Perbanas Surabaya \\
& Perpustakaan & & tema “Kampusku untuk & dan Perpustakaan \\
& & & cita-citaku”. (Kumpulan & Sekolah \\
& & CerPen terbaik akan & \\
& & diterbitkan menjadi & \\
& & Buku) & \\
\hline
\end{tabular}




\section{Pengajuan proposal dan perijinan lokasi pengabdian}

\section{Pengajuan Proposal kepada Pihak Internal}

Proposal kegiatan "Pengabdian Perpustakaan STIE Perbanas Surabaya Kepada Masyarakat Melalui Membangun Atmosfer Akademik Literasi Sekolah Di SMAN 15 Surabaya dan SMA Wachid Hasyim 1 Surabaya" yang telah selesai disusun tahapan selanjutnya adalah membuat permohonan persetujuan kepada Pimpinan STIE Perbanas Surabaya agar dapat memberikan persetujuan untuk melaksanakan kegiatan pengabdian perpustakaan kepada pihak eksternal yakni pada sekolah-sekolah yang sudah ditargetkan. Setelah memperoleh persetujuan oleh Pimpinan STIE Perbanas Surabaya maka dapat dilanjutkan untuk penyampaian proposal kegiatan kepada Sekolah yang ditargetkan.

\section{Perijinan Kegiatan Pengabdian kepada Sekolah}

Proses perijinan kegiatan "Pengabdian Perpustakaan STIE Perbanas Surabaya Kepada Masyarakat Melalui Membangun Atmosfer Akademik Literasi Sekolah Di SMAN 15 Surabaya dan SMA Wachid Hasyim 1 Surabaya" dimulai dengan koordinasi antara Perpustakaan STIE Perbanas Surabaya dengan kepala perpustakaan sekolah atau ketua literasi sekolah, dan dilanjutkan dengan perijinan kepada Kepala Sekolah SMAN 15 Surabaya dan SMA Wachid Hasyim Surabaya sampai dengan perijinan kegiatan memperoleh persetujuan dari Kepala Sekolah.

\section{Pelaksanaan Kegiatan}

Penentuan jadwal pelaksanaan kegiatan "Pengabdian Perpustakaan STIE Perbanas Surabaya Kepada Masyarakat Melalui Membangun Atmosfer Akademik Literasi Sekolah Di SMAN 15 Surabaya dan SMA Wachid Hasyim 1 Surabaya" ini ditentukan melalui usulan tanggal kegiatan dari masingmasing pihak sekolah dari hasil diskusi dengan pihak sekolah maka kegiatan pengabdian dilaksanakan pada:

- SMAN 15 Surabaya 
Peningkatan Literasi Sekolah Guru dan Siswa melalui Pengabdian Kepada Masyarakat Perpustakaan STIE Perbanas Surabaya

Hari, Tanggal : : Rabu, 24 Januari 2018

Pukul

: 09.00-Selesai

Tempat

: Aula SMAN 15 Surabaya

- SMA Wachid Hasyim Surabaya

Hari, Tanggal : : Sabtu, 27 Januari 2018

Pukul

: 09.00-Selesai

Tempat

: Ruang Multimedia SMA Wachid Hasyim Surabaya

\section{Sharing kegiatan Literasi Informasi dengan Guru}

Sharing kegiatan literasi informasi dengan guru mengenai kegiatan literasi informasi yang telah dilaksanakan Perpustakaan Perbanas Surabaya yang diantaranya:

- Perkembangan Literasi Informasi di Sekolah

- Pentingnya Literasi Informasi untuk siswa

- Karakteristik Siswa Net Generation

- Aktivitas Gerakan Literasi Sekolah sesuai dengan buku pedoman KEMENDIKBUD

- Kolaborasi Guru, Pustakawan dan Perpustakaan Sekolah untuk mensukseskan gerakan literasi sekolah

- Sharing kegiatan literasi informasi di Perpustakaan STIE Perbanas Surabaya

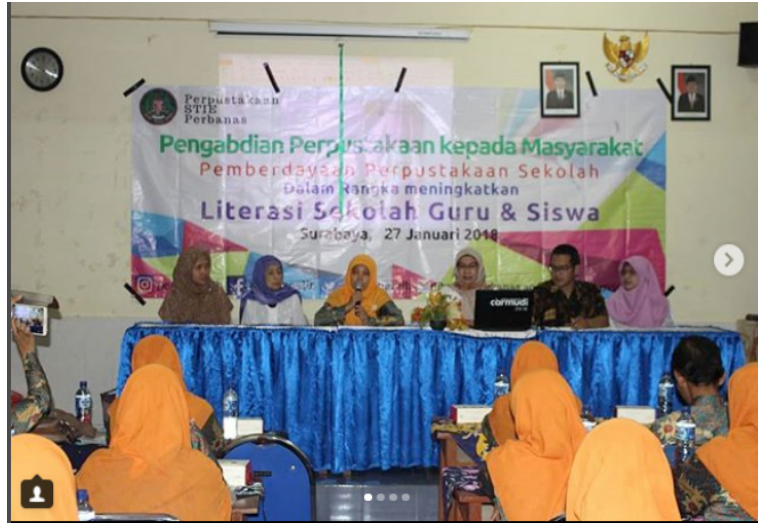

Gambar 1. Kegiatan Sharing dengan Guru 


\section{Ceramah Perpustakaan mengenai Literasi Sekolah kepada Siswa}

Pada sesi ceramah ini diikuti oleh perwakilan siswa-siswa di masingmasing sekolah yakni siswa SMAN 15 Surabaya dan SMA Wachid Hasyim Surabaya yakni mengenai "Pemanfaatan Perpustakaan Sekolah untuk Literasi Sekolah" yang memaparkan mengenai:

- Fungsi Perpustakaan Sekolah

- Jenis-Jenis koleksi yang terdapat di Perpustakan Sekolah

- Pemanfaatan perpustakaan sekolah dari segi koleksi dan tempat

- Langkah-langkah menemukan koleksi di Perpustakaan

- Pemanfaatan e-library open access

- Sharing aktivitas literasi informasi di Perpustakaan STIE Perbanas Surabaya
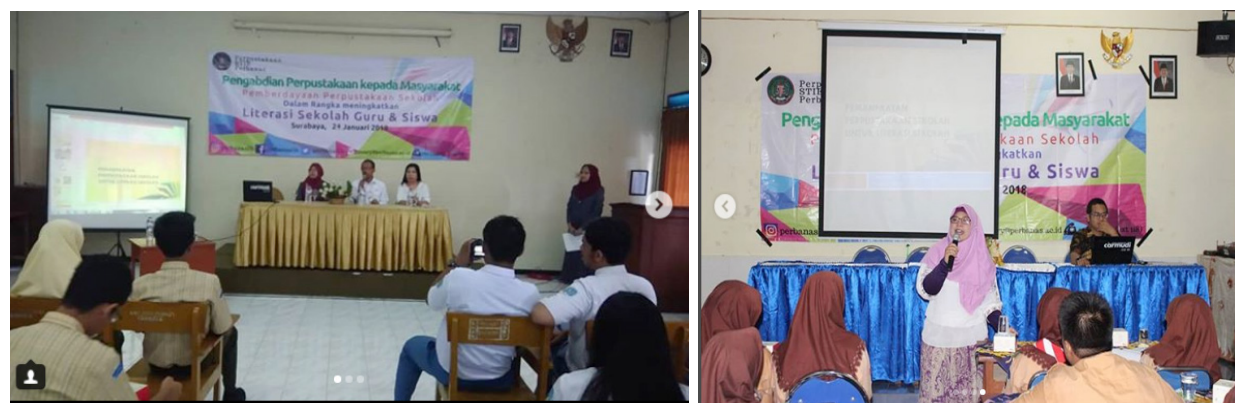

Gambar 2. Kegiatan Ceramah Literasi Sekolah kepada Siswa

\section{Hasil Kegiatan Pengbdian Perpustakaan}

\begin{tabular}{clll}
\hline No & \multicolumn{1}{c}{ Aktivitas } & Materi Pengabdian & \multicolumn{1}{c}{ Output } \\
\hline $\mathbf{1}$ & Sharing & Membangun & 1. Minat memanfaatkan media \\
& kegiatan Literasi & Atmosfer Akademik & pembelajaran interaktif seperti \\
& Informasi & Literasi Sekolah & e-learning yang terlihat pada saat \\
& dengan Guru & & sesi sharing dan diskusi. \\
& & 2. MoU Kerjasama dengan pihak \\
& & & sekolah terkait pelaksanaan Literasi \\
& & & Sekolah \\
\hline
\end{tabular}




\begin{tabular}{|c|c|c|c|}
\hline No & Aktivitas & Materi Pengabdian & Output \\
\hline 2 & $\begin{array}{l}\text { Ceramah } \\
\text { Perpustakaan } \\
\text { mengenai } \\
\text { Literasi Sekolah } \\
\text { kepada Siswa }\end{array}$ & $\begin{array}{l}\text { Pemanfaatan } \\
\text { Perpustakaan Sekolah } \\
\text { untuk Literasi Sekolah }\end{array}$ & $\begin{array}{l}\text { 1. Pemanfaatan Perpustakaan Sekolah } \\
\text { untuk pemenuhan kebutuhan } \\
\text { informasi dengan adanya kelas } \\
\text { literasi di Perpustakaan } \\
\text { 2. Hasil evaluasi dalam bentuk kuis } \\
\text { online menggunakan quizizz setelah } \\
\text { materi ceramah dan diskusi literasi } \\
\text { dengan hasil tingkat pemahaman } \\
\text { mengenai literasi di kedua sekolah } \\
\text { sebesar } 63 \%\end{array}$ \\
\hline 3 & $\begin{array}{l}\text { Perwujudan dari } \\
\text { Literasi Dasar } \\
\text { dan Literasi } \\
\text { Perpustakaan }\end{array}$ & $\begin{array}{l}\text { Lomba Menulis } \\
\text { Cerpen }\end{array}$ & $\begin{array}{l}\text { Penerbitan Buku Kumpulan Cerpen } \\
\text { ber-ISBN } \\
{ }^{\star} \text { Sedang Berlangsung* }\end{array}$ \\
\hline
\end{tabular}

\section{Kesimpulan}

Dari rangkaian kegiatan "Pengabdian Perpustakaan STIE Perbanas Surabaya Kepada Masyarakat Melalui Membangun Atmosfer Akademik Literasi Sekolah Di SMAN 15 Surabaya dan SMA Wachid Hasyim 1 Surabaya” keseluruhan rangkaian acara untuk sharing dengan guru dan siswa berjalan dengan lancar, dan mendapatkan apresiasi positif dari pihak sekolah, yakni dilihat dari proses perijinan sampai dengan pelaksanaan sekolah mendukung penuh kegiatan yang dilaksanakan. Kedepannya pihak sekolah berharap agar kerjasama terkait dengan keberhasilan aktivitas literasi sekolah agar dapat lebih dikembangkan dengan adanya tambahan-tambahan informasi yang disampaikan pihak Perpustakaan STIE Perbanas Surabaya secara berkala dalam bentuk sharing atau diskusi. Dan diharapkan ke terdapat kerjasamakerjasama bentuk lain dengan STIE Perbanas Surabaya seperti pelatihan komputer, elearning untuk guru-guru. Terkait dengan kegiatan literasi yang sudah dilakukan oleh kedua sekolah perlu dilakukan pengembangan kegiatan untuk pemenuhan literasi media, visual dan teknologi. Keterlibatan siswa untuk berkolaborasi dengan perpustakaan perlu dilakukan untuk dapat meningkatkan literasi dan mendukung terciptanya kreatifitas-kreatifitas siswa. 


\section{Daftar Pustaka}

Candy, P. C. (2002). Life Learning and Information Literacy. In U.S. National Commission on Libraries and Information Science, and the National Forum on Information Literacy, Meeting of Experts, Prague, The Czech Republic. Prague: UNESCO.

Direktorat Jenderal Pendidikan Dasar dan Menengah Kementerian Pendidikan dan Kebudayaan. (2016). Panduan Gerakan Literasi Sekolah di Sekolah Menengah Atas. (Direktorat Jenderal Pendidikan Dasar dan Menengah Kementerian Pendidikan dan Kebudayaan, Ed.). Jakarta: Direktorat Jenderal Pendidikan Dasar dan Menengah Kementerian Pendidikan dan Kebudayaan.

Ranaweera, P. (2008). Importance of Information Literacy skills for an Information Literate society. In NACLIS (pp. 1-13). Colombo: NACLIS.

Suryani, T. (2013). Perilaku Konsumen di Era Internet: Implikasinya pada Strategi Pemasaran. Yogyakarta: Graha Ilmu. 